\title{
Symptom-Triggered Therapy for Alcohol Withdrawal Syndrome: a Systematic Review and Meta-analysis of Randomized Controlled Trials
}

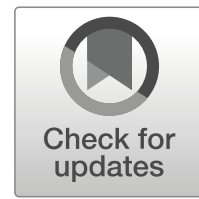

\author{
Jürgen L. Holleck, M.D. ${ }^{1,2}$, Naseema Merchant, M.D. ${ }^{1,2}$, and Craig G. Gunderson, M.D. ${ }^{1,2}$ \\ 'Department of Internal Medicine, Yale University School of Medicine, New Haven, CT, USA; ${ }^{2}$ Department of Medicine, West Haven VA Hospital, \\ Veterans Affairs Connecticut Healthcare System, West Haven, CT, USA.
}

\begin{abstract}
BACKGROUND: Benzodiazepines are the standard medication class for treating alcohol withdrawal. Guidelines recommend dosing based on objectively measured symptoms (symptom-triggered therapy) rather than fixed dose regimens. However, the superiority of symptom-triggered therapy has been questioned, and concerns have been raised about its inappropriate use and safety. We aimed to assess whether symptom-triggered therapy is superior to fixed dose schedules in terms of mortality, delirium, seizures, total benzodiazepine dose, and duration of therapy.
\end{abstract}

METHODS: A systematic literature search using Medline, Embase, and the Cochrane Registry through February 2018 was conducted for randomized controlled trials of patients with alcohol withdrawal syndrome comparing fixed dose benzodiazepine schedules to symptomtriggered therapy. Risk of bias was assessed using the Cochrane Risk of Bias Tool. Outcomes were pooled using random effects meta-analysis. Heterogeneity was estimated using the $I^{2}$ statistic. Strength of evidence was assessed using methods outlined by the Agency for Healthcare Research and Quality.

RESULTS: Six studies involving 664 patients were included. There were no deaths and only one seizure in each group. Four studies reported delirium, which occurred in 4 out of 164 patients randomized to symptom-triggered therapy compared to 6 out of 164 randomized to fixed dose therapy (odds ratio, 0.64 [95\% CI, 0.17-2.47]). Three studies reported duration of therapy, which was $60.4 \mathrm{~h}$ less with symptom-triggered therapy (95\% CI, 39.7$81.1 \mathrm{~h} ; p<0.001)$. Six studies reported total benzodiazepine dosage, which was $10.5 \mathrm{mg}$ in lorazepam-equivalent dosing less with symptom-triggered therapy (95\% CI, 7.1$13.9 \mathrm{mg} ; p=0.011$ ).

DISCUSSION: Moderate strength evidence suggests that symptom-triggered therapy improved duration of therapy and total benzodiazepine dose in specialized detoxification settings of low-risk patients but the applicability of this evidence in general hospital settings is low. There was insufficient evidence for any conclusions about symptom-

Prior Presentations The contents of this manuscript were previously presented at the New England Regional Society of General Internal Medicine Meeting in March 2018 and at the National Society of Hospital Medicine Meeting in April 2018.

Received August 30, 2018

Revised November 20, 2018

Accepted February 5, 2019

Published online April 1, 2019 triggered therapy for the major outcomes of mortality, seizure, and delirium in any setting.

PROSPERO REGISTRATION: CRD42017073426

KEY WORDS: alcohol withdrawal delirium; benzodiazepines; evidencebased medicine; meta-analysis.

J Gen Intern Med 34(6):1018-24

DOI: $10.1007 / \mathrm{s} 11606-019-04899-7$

(C) Society of General Internal Medicine (This is a U.S. government work and not under copyright protection in the U.S.; foreign copyright protection may apply) 2019

\section{INTRODUCTION}

Alcohol use disorder and alcohol withdrawal syndrome are common problems in hospitals and emergency rooms. The lifetime prevalence of alcohol use disorder in the USA is $29 \%$ [1], and it is present in $25 \%$ of hospitalized medical patients [2]. Approximately $50 \%$ of patients with alcohol use disorder experience withdrawal symptoms upon cessation, including $5 \%$ who have severe symptoms such as seizure and delirium [3]. Benzodiazepines are generally considered the standard medication class for treating alcohol withdrawal syndrome [3-5]. Numerous review articles and guidelines have been written recommending that dosing of benzodiazepines be based on objectively measured symptoms of withdrawal rather than fixed dose regimens $[3,6,7]$. The most commonly recommended scale for measuring withdrawal is the revised Clinical Institute Withdrawal Assessment for Alcohol (CIWA-Ar) scale [8]. Nevertheless, some authors have questioned the superiority of symptom-triggered therapy [9]. It has also been reported that hospitalized patients without alcohol use disorder may be placed on symptom-triggered protocols inappropriately [10] and that adding a symptom-triggered component based on CIWA scores to protocols at one hospital was associated with increased mortality and length of stay [11]. The literature supporting symptomtriggered therapy has also been questioned for being unrepresentative of general medical inpatients [12]. Given this uncertainty, we undertook a systematic review of all randomized controlled studies comparing symptom-triggered therapy to fixed dose schedules to assess whether symptom-triggered therapy was associated with improved mortality, delirium, seizure, duration of therapy, and total dose of benzodiazepine. 


\section{METHODS}

\section{Data Sources and Search Strategy}

A systematic literature search using Medline, Embase, and the Cochrane Registry from database inception through February 12, 2018, was conducted for randomized controlled trials of patients with alcohol withdrawal syndrome comparing fixed dose benzodiazepine schedules to symptom-triggered therapy. Symptom-triggered therapy was defined as any regimen using a standardized withdrawal scale to dose medication as needed without a standing order. Fixed dose was defined as any regimen using fixed doses with or without additional as needed medication. We derived search terms using the medical subject heading terms from studies on the subject known by the authors. For Medline, we used the following search strategy: (("substance withdrawal syndrome/drug therapy AND comparative study")) OR ((alcohol withdrawal delirium/drug therapy OR alcohol withdrawal delirium/prevention and control)). We did not apply any search limitations. The review protocol was registered in the PROSPERO database (registration CRD42017073426). The Preferred Reporting Items for Systematic Reviews and Meta-analyses (PRISMA) guidelines were used for planning and reporting our review [13].

\section{Study Selection}

Two reviewers ( $\mathrm{JH}$ and NM) independently screened titles and abstracts for full text review. Only randomized controlled studies for management of alcohol withdrawal with benzodiazepines comparing fixed dose schedules to symptomtriggered therapy were included; observational studies were excluded. Disagreement was resolved by consensus.

\section{Data Extraction and Quality Assessment}

We used a standardized form to extract data which included author, year, country, study design, number of patients, specific medication and dosing for the fixed dose and symptomtriggered arms, method used for assessing symptom severity, study setting, and reported outcomes including mortality, seizure, delirium, total benzodiazepine dose, and duration of therapy/length of stay. Two reviewers (JH and NM) independently assessed the methodological quality of included studies using the Cochrane Risk of Bias Tool [14]. Additionally, two reviewers (J.H., C.G.) graded overall strength of evidence for each outcome based on study risk of bias, directness, consistency, and precision as recommended by the Agency for Healthcare Research and Quality [15]. Disagreement was resolved by consensus.

\section{Data Synthesis and Analysis}

For dichotomous outcomes such as delirium, we calculated odds ratios when sufficient data was available. For continuous variables, we used means and standard deviations to calculate mean differences in outcomes between symptom-triggered groups and fixed dose groups. If means and standard deviations were not available, we estimated values using the median and range based on methods from Luo et al. and Wan et al. $[16,17]$ For the outcome of total benzodiazepine dose given, we first converted to lorazepam equivalents by dividing oxazepam doses by 15 , chlordiazepoxide by 25 , and diazepam by 5 $[18,19]$. All meta-analyses were done using random effects meta-analysis. Heterogeneity was estimated using the $I^{2}$ statistic. Statistical analysis was performed using Stata/SE, version 14.2 (StataCorp, College Station, TX).

\section{RESULTS}

\section{Selected Studies}

The electronic search yielded 1589 unique manuscripts of which 1578 were excluded based on title and abstract leaving 11 manuscripts for full-text review. Ultimately, six studies met inclusion criteria (Fig. 1). Table 1 describes the characteristics of these six studies. Studies were published between 1994 and 2014. Three studies were performed in the USA $[9,19,20]$, two from Europe [21,22], and one from India [23]. One study occurred in an outpatient setting [22] and five were described as inpatient studies although upon closer review, these were mostly specialized detoxification centers excluding those with acute illness or comorbidities rather than traditional hospitalized patients on general medical or surgical wards (Table 1). Two trials used chlordiazepoxide [19,22], two used lorazepam [20,23], one used oxazepam [21], and one used both diazepam and lorazepam [9]. Sample size ranged from 47 to 183 patients. Most patients were male and study mean ages ranged from 38.6 to 51.7 years. All six studies reported deaths, seizures, and total benzodiazepine given. Four studies reported on the occurrence of delirium $[9,19,21,23]$ and three studies reported on duration of therapy. [19,21,23]

Table 2 describes the risk of bias assessment using the Cochrane Risk of Bias Tool. Most studies had some type of bias that was rated as unclear or high risk of bias, including bias related to randomization and blinding. Reporting bias was generally rated as low except for the study by Weaver which for the outcome of total benzodiazepine appeared to report only on the subset of patients that had data on CIWA-Ar scores. Several studies were also rated as high risk of bias for the outcomes of duration of treatment and total benzodiazepine given because of a design bias [19-21]. These studies included a large proportion of low-risk patients that did not initially have symptoms of withdrawal and did not go on to develop symptoms of withdrawal. The limitation with this is that patients in the symptom-triggered group would therefore by definition receive less medication than the fixed dose group who automatically received the full amount of benzodiazepine specified by the protocol. In the study by Daeppen for 


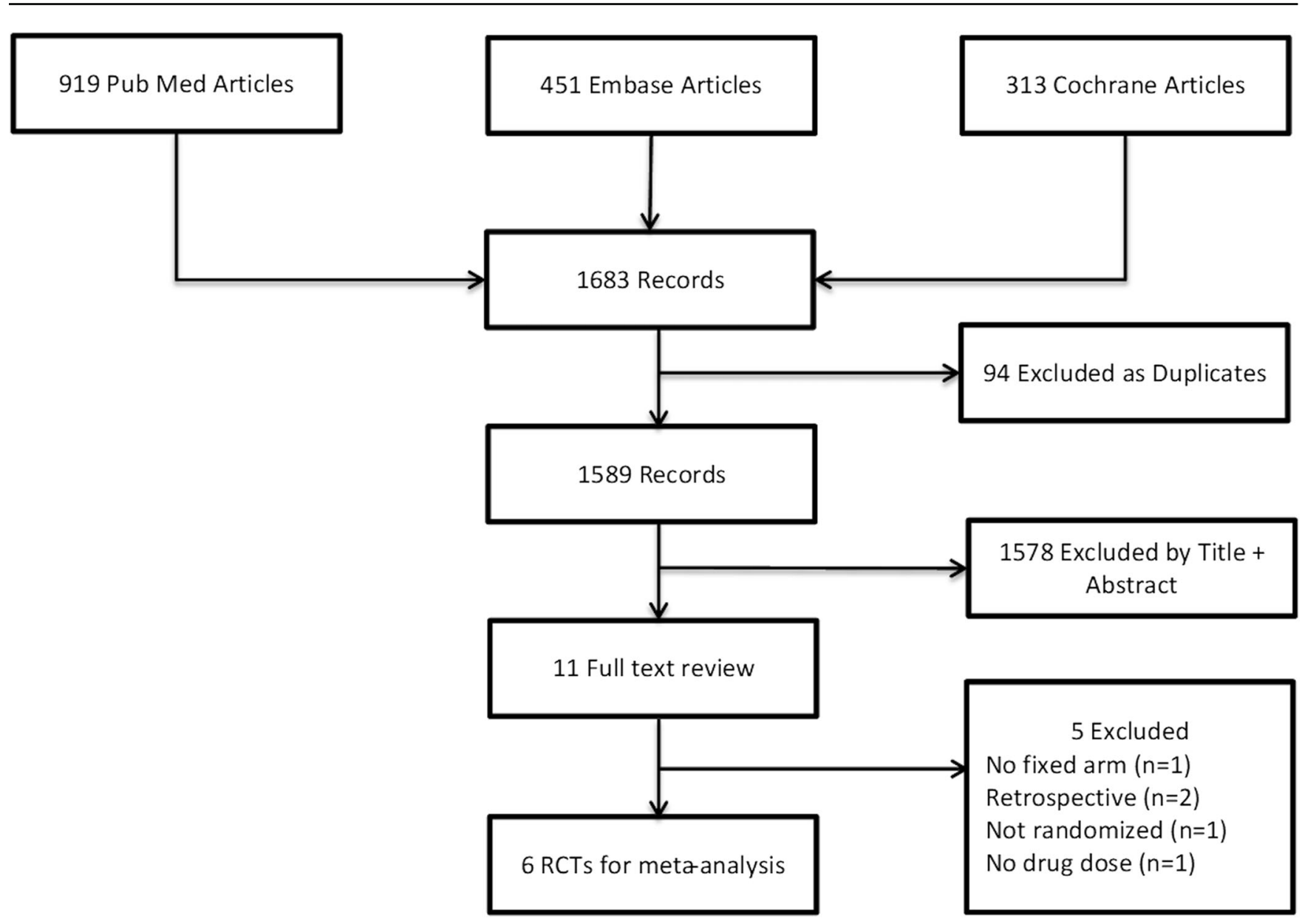

Figure 1 Study flow diagram of literature search.

example, $60 \%$ of patients in the symptom-triggered therapy group never developed symptoms of withdrawal and therefore did not receive any study medication. A fairer way to test symptom-triggered therapy vs. fixed dose for the outcomes of total dose and duration would be to enroll only patients currently manifesting symptoms of withdrawal, such as CIWAAr scores above 8-12.

\section{Quantitative Outcomes}

Table 3 summarizes our review findings. For the major outcomes of mortality, seizures, and delirium, there were too few events to allow meaningful comparisons. There were no deaths in any of the studies and only one seizure in each arm. For delirium, there were four events in the symptom-triggered group compared with six in the fixed dose group, although the resultant odds ratio was not significantly different. Figure 2 presents the individual study and pooled results for total benzodiazepine dose. The overall difference was $10.5 \mathrm{mg}$ in lorazepam-equivalent dosing less (95\% CI, 7.1-13.9 mg; $p=0.011$ ) favoring symptomtriggered therapy. Figure 3 presents the difference in mean duration of treatment between the two groups. The overall pooled difference was $60.4 \mathrm{~h}$ less in the symptom-triggered group (95\% CI, 39.7-81.1 h). There was statistically significance evidence for heterogeneity for difference in mean total benzodiazepine dose $\left(I^{2}=66.3 \%, p=0.003\right)$ and for duration of therapy $\left(I^{2}=91.2 \%, p<0.001\right)$.

\section{Strength of Evidence}

For the outcomes of mortality, seizure, and delirium, there were too few events to draw conclusions on symptomtriggered therapy and the overall strength of evidence was rated as insufficient. For the outcomes of mean difference in total benzodiazepine and mean difference in duration of detoxification, the overall strength of evidence was rated moderate. For most components of strength of evidence such as directness, consistency, and precision, the studies rated well. For the component of study limitations, randomized controlled studies start as high strength of evidence. We downgraded these to moderate strength for these outcomes based on the design limitation related to enrolling low-risk patients without symptoms of withdrawal. We rated applicability separately from strength of evidence. For specialized detoxification centers, we rated applicability as high. For hospitalized patients with illness or comorbidities on general medical or surgical wards, we rated applicability as low. 
Table 1 Characteristics of Selected Papers

\begin{tabular}{|c|c|c|c|c|c|c|}
\hline $\begin{array}{l}\text { Author/ } \\
\text { year }\end{array}$ & $N$ & Setting & $\begin{array}{l}\text { Patient } \\
\text { population }\end{array}$ & Interventions & Study criteria & Outcomes \\
\hline Saitz 1994 & 101 & $\begin{array}{l}\text { Single inpatient } \\
\text { detoxification center in } \\
\text { the USA }\end{array}$ & $\begin{array}{l}47 \text { years } \\
99 \% \text { male } \\
\text { veterans }\end{array}$ & $\begin{array}{l}\text { Chlordiazepoxide fixed } \\
+ \text { prn vs prn only }\end{array}$ & $\begin{array}{l}\text { ETOH abuse or } \\
\text { dependence DSM3. } \\
\text { Exclusions: seizures; acute } \\
\text { med/psych hospitalization }\end{array}$ & $\begin{array}{l}\text { Deaths, delirium, } \\
\text { seizure, duration, total } \\
\text { benzodiazepine dose }\end{array}$ \\
\hline $\begin{array}{l}\text { Daeppen } \\
2002\end{array}$ & 117 & $\begin{array}{l}\text { Two inpatient } \\
\text { detoxification centers in } \\
\text { Switzerland }\end{array}$ & $\begin{array}{l}46.6 \text { years } \\
76.9 \% \text { male }\end{array}$ & $\begin{array}{l}\text { Oxazepam fixed }+ \text { prn } \\
\text { vs prn only }\end{array}$ & $\begin{array}{l}\text { Inpatient ETOH program. } \\
\text { Exclusions: abstinence } \\
<72 \text { h; major cognitive, } \\
\text { psych or medical } \\
\text { comorbidity }\end{array}$ & $\begin{array}{l}\text { Deaths, delirium, } \\
\text { seizure, duration, total } \\
\text { benzodiazepine dose }\end{array}$ \\
\hline $\begin{array}{l}\text { Weaver } \\
2006\end{array}$ & 183 & $\begin{array}{l}\text { General medical service } \\
\text { in single hospital in the } \\
\text { USA }\end{array}$ & $\begin{array}{l}48.9 \text { years } \\
80.9 \% \text { male }\end{array}$ & $\begin{array}{l}\text { Lorazepam fixed dose }+ \\
\text { prn vs lorazepam prn }\end{array}$ & $\begin{array}{l}\text { Age } 21-75 \text { with } \mathrm{AD} ; \text { ab- } \\
\text { stinent }<72 \mathrm{~h} \text {; admit to } \\
\text { medicine service }\end{array}$ & $\begin{array}{l}\text { Deaths, seizure, total } \\
\text { benzodiazepine dose }\end{array}$ \\
\hline Elhom 2011 & 165 & $\begin{array}{l}\text { Outpatient Treatment } \\
\text { Center in Denmark }\end{array}$ & $\begin{array}{l}49 \text { years } \\
83.7 \% \text { male }\end{array}$ & $\begin{array}{l}\text { Chlordiazepoxide fixed } \\
\text { dose vs prn only }\end{array}$ & $\begin{array}{l}\text { Age }>18, \mathrm{ICD}-10 \mathrm{AD} \text { and } \\
\text { AWS and abstinence }< \\
72 \mathrm{~h} \\
\text { Exclusions: dementia, } \\
\text { severe cardiac, liver or } \\
\text { psychiatric disease }\end{array}$ & $\begin{array}{l}\text { Deaths, seizure, total } \\
\text { benzodiazepine dose }\end{array}$ \\
\hline $\begin{array}{l}\text { Maldonado } \\
2012\end{array}$ & 47 & $\begin{array}{l}\text { Various services at two } \\
\text { hospitals in the USA ( } 3 \\
\text { of } 47 \text { general medical } \\
\text { service) }\end{array}$ & $\begin{array}{l}51.7 \text { years } \\
97.9 \% \text { male }\end{array}$ & $\begin{array}{l}\text { Diazepam fixed dose }+ \\
\text { prn vs lorazepam prn } \\
\text { only }\end{array}$ & $\begin{array}{l}\text { Adult inpatients with } \\
\text { ETOH withdrawal or } \\
\text { dependence. } \\
\text { Exclusions: dementia, } \\
\text { severe liver disease }\end{array}$ & $\begin{array}{l}\text { Deaths, delirium, } \\
\text { seizure, total } \\
\text { benzodiazepine dose }\end{array}$ \\
\hline $\begin{array}{l}\text { Sachdeva } \\
2014\end{array}$ & 63 & $\begin{array}{l}\text { Single inpatient } \\
\text { detoxification center in } \\
\text { India. }\end{array}$ & $\begin{array}{l}38.6 \text { years } \\
100 \% \text { male }\end{array}$ & $\begin{array}{l}\text { Lorazepam fixed dose }+ \\
\text { prn vs lorazepam prn } \\
\text { only }\end{array}$ & $\begin{array}{l}\text { Age } 18-60 \text { with AD and } \\
\text { uncomplicated withdraw- } \\
\text { al. } \\
\text { Exclusions: AUDIT < } 10 \text {; } \\
\text { major psychiatric or } \\
\text { medical disease, dementia, } \\
\text { delirium }\end{array}$ & $\begin{array}{l}\text { Deaths, delirium, } \\
\text { seizure, duration, total } \\
\text { benzodiazepine dose }\end{array}$ \\
\hline
\end{tabular}

\section{DISCUSSION}

In total, we found six randomized controlled studies comparing symptom-triggered to fixed dose benzodiazepine regimens. For the major outcomes of mortality, seizures, and delirium, there were too few events to allow meaningful comparison. Small sample sizes and low-risk populations contributed to this. For example, sample sizes ranged from only 47 [9] to 183 [20]. Likewise, a low-risk population can be inferred from the fact that $61 \%$ of patients receiving symptomtriggered therapy in one study did not require a single dose of benzodiazepines [21], or that mean duration of therapy with symptom-triggered therapy was only $9 \mathrm{~h}$ in another [19], or that $73 \%$ of symptom-triggered therapy patients in a third study [20] had CIWA-Ar scores below 6 initially and only required an average of $4 \mathrm{mg}$ of lorazepam for the entire detoxification regimen. A fourth study was low enough risk that detoxification could be performed in the outpatient setting [22]. This leaves only two remaining studies with what appeared to be higher risk populations, one with mean CIWA-Ar scores of 8 upon admission [9] and the other with mean CIWA-Ar scores of 15.5 upon admission [23].

The two outcomes with sufficient data were total benzodiazepine dose and duration of therapy which were significantly less with symptom-triggered therapy compared to

Table 2 Quality Assessment of Included RCT Studies Using the Cochrane Collaboration Tool for Assessing Risk of Bias

\begin{tabular}{|c|c|c|c|c|c|c|c|}
\hline \multirow[t]{2}{*}{ Reference } & \multirow{2}{*}{$\begin{array}{l}\text { Selection bias } \\
\text { Random } \\
\text { sequence } \\
\text { generation }\end{array}$} & \multirow{2}{*}{$\begin{array}{l}\text { Performance } \\
\text { Allocation } \\
\text { concealment }\end{array}$} & \multirow{2}{*}{$\begin{array}{l}\text { Detection bias } \\
\text { Blinding of } \\
\text { participants and } \\
\text { personnel }\end{array}$} & \multirow{2}{*}{$\begin{array}{l}\text { Attrition bias } \\
\text { Blinding of } \\
\text { outcome } \\
\text { assessment }\end{array}$} & \multirow{2}{*}{$\begin{array}{l}\text { Reporting bias } \\
\text { Incomplete } \\
\text { outcome data }\end{array}$} & \multirow[b]{2}{*}{$\begin{array}{l}\text { Selective } \\
\text { reporting }\end{array}$} & \multirow{2}{*}{$\begin{array}{l}\begin{array}{l}\text { Other } \\
\text { bias }\end{array} \\
\begin{array}{l}\text { Other } \\
\text { bias * }\end{array}\end{array}$} \\
\hline & & & & & & & \\
\hline Saitz et al. & $\mathrm{U}$ & $\mathrm{L}$ & $\mathrm{L}$ & $\mathrm{L}$ & $\mathrm{L}$ & $\mathrm{L}$ & $\mathrm{H}$ \\
\hline $\begin{array}{l}\text { Daeppen } \\
\text { et al. }\end{array}$ & $\mathrm{L}$ & $\mathrm{L}$ & $\mathrm{L}$ & $\mathrm{L}$ & $\mathrm{L}$ & $\mathrm{L}$ & $\mathrm{H}$ \\
\hline Weaver et al. & $\mathrm{U}$ & $\mathrm{U}$ & $\mathrm{U}$ & $\mathrm{U}$ & $\mathrm{U}$ & $\mathrm{U}$ & $\mathrm{H}$ \\
\hline Elholm et al. & $\mathrm{L}$ & $\mathrm{L}$ & $\mathrm{U}$ & $\mathrm{U}$ & $\mathrm{L}$ & $\mathrm{L}$ & U \\
\hline $\begin{array}{l}\text { Maldonado } \\
\text { et al. }\end{array}$ & $\mathrm{L}$ & $\mathrm{L}$ & $\mathrm{H}$ & $\mathrm{L}$ & $\mathrm{L}$ & $\mathrm{L}$ & $\mathrm{L}$ \\
\hline $\begin{array}{l}\text { Sachdeva } \\
\text { et al. }\end{array}$ & $\mathrm{L}$ & $\mathrm{L}$ & $\mathrm{L}$ & $\mathrm{L}$ & $\mathrm{L}$ & $\mathrm{L}$ & $\mathrm{U}$ \\
\hline
\end{tabular}

$L$, low risk of bias; $H$, high risk of bias; $U$, unclear risk of bias

*Design bias for particular outcomes 
Table 3 Summary of Outcomes

\begin{tabular}{|c|c|c|c|c|c|c|}
\hline$\overline{\text { Outcome }}$ & $\begin{array}{l}\text { No. of } \\
\text { studies }\end{array}$ & $\begin{array}{l}\text { Symptom } \\
\text { triggered }\end{array}$ & $\begin{array}{l}\text { Fixed } \\
\text { dose }\end{array}$ & $\begin{array}{l}\text { Odds ratio } \\
(95 \% \text { CI) }\end{array}$ & $\begin{array}{l}\text { Strength of } \\
\text { evidence }\end{array}$ & Applicability \\
\hline \multicolumn{7}{|l|}{ Major outcomes } \\
\hline Mortality & 6 & $0 / 333$ & $0 / 331$ & - & Insufficient & Insufficient \\
\hline Seizure & 6 & $1 / 333$ & $1 / 331$ & - & Insufficient & Insufficient \\
\hline Delirium & 4 & $4 / 164$ & $6 / 164$ & $0.64(0.2-2.5)$ & Insufficient & Insufficient \\
\hline Other outcomes & & & & $\begin{array}{l}\text { Mean difference }(95 \% \\
\text { CI) }\end{array}$ & & \\
\hline $\begin{array}{l}\text { Mean difference in } \\
\text { total }\end{array}$ & 6 & - & - & $-10.5(-13.9,-7.1)$ & Moderate & High/low* \\
\hline $\begin{array}{l}\text { benzo (milligrams) } \\
\text { Mean difference } \\
\text { (hours) }\end{array}$ & 3 & - & - & $-60.4(-81.1,-39.7)$ & Moderate & High/low* \\
\hline
\end{tabular}

*For inpatient detoxification centers of low-risk patients, applicability was rated as high. For hospitalized patients on medical or surgical wards, applicability was rated as low

fixed dose therapy. In fact, treatment duration was $2 \frac{1}{2}$ days less with symptom-triggered therapy and one might think this could have significant ramifications for length of stay in this era of seeking to provide cost effective care. However, there was significant bias in design for duration of therapy and total benzodiazepine amount. This occurred because of the low-risk populations mentioned in the preceding paragraph. For example, 34 of the 56 patients in the symptom-triggered group of one study did not receive any medication during the study while the analogous 34 patients in the fixed schedule group automatically received a minimum of $16 \mathrm{mg}$ of lorazepam-equivalent medication per study protocol [21]. By including a large group of patients that did not develop significant withdrawal symptoms and therefore did not receive any medication in the symptom-triggered arm, these studies basically guaranteed that the fixed schedule group would receive more study medication and be treated for a greater duration. It is also important to note that a duration of therapy of $9 \mathrm{~h}$ in one study's symptom-triggered therapy group [19] or $20 \mathrm{~h}$ in another [21] does not correlate to length of stay given that alcohol withdrawal and risk of delirium tremens persists beyond that. These patients were monitored an additional $24 \mathrm{~h}$ in the first study and at least 3 days in the latter.

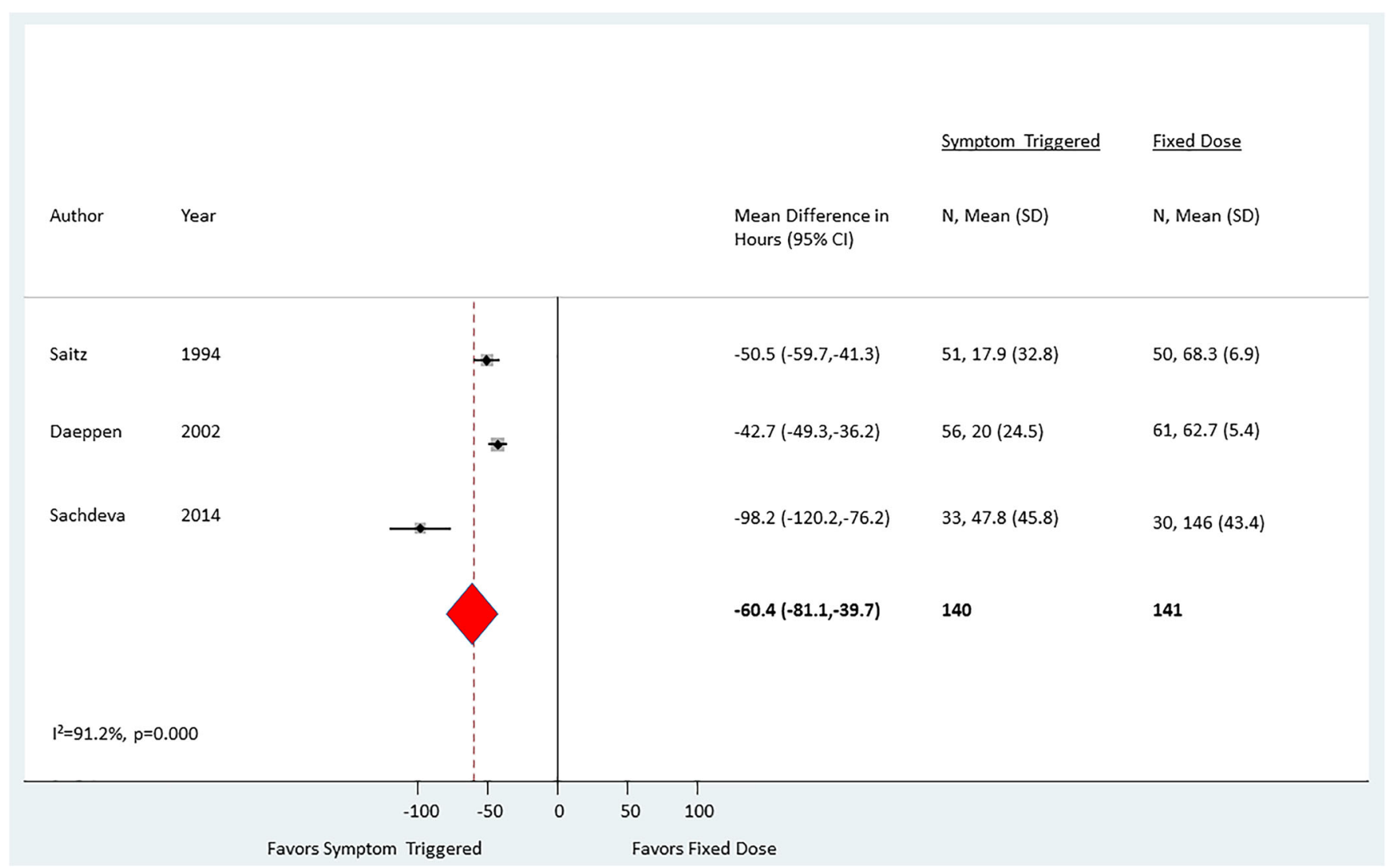

Figure 2 Difference in duration of treatment in hours. 


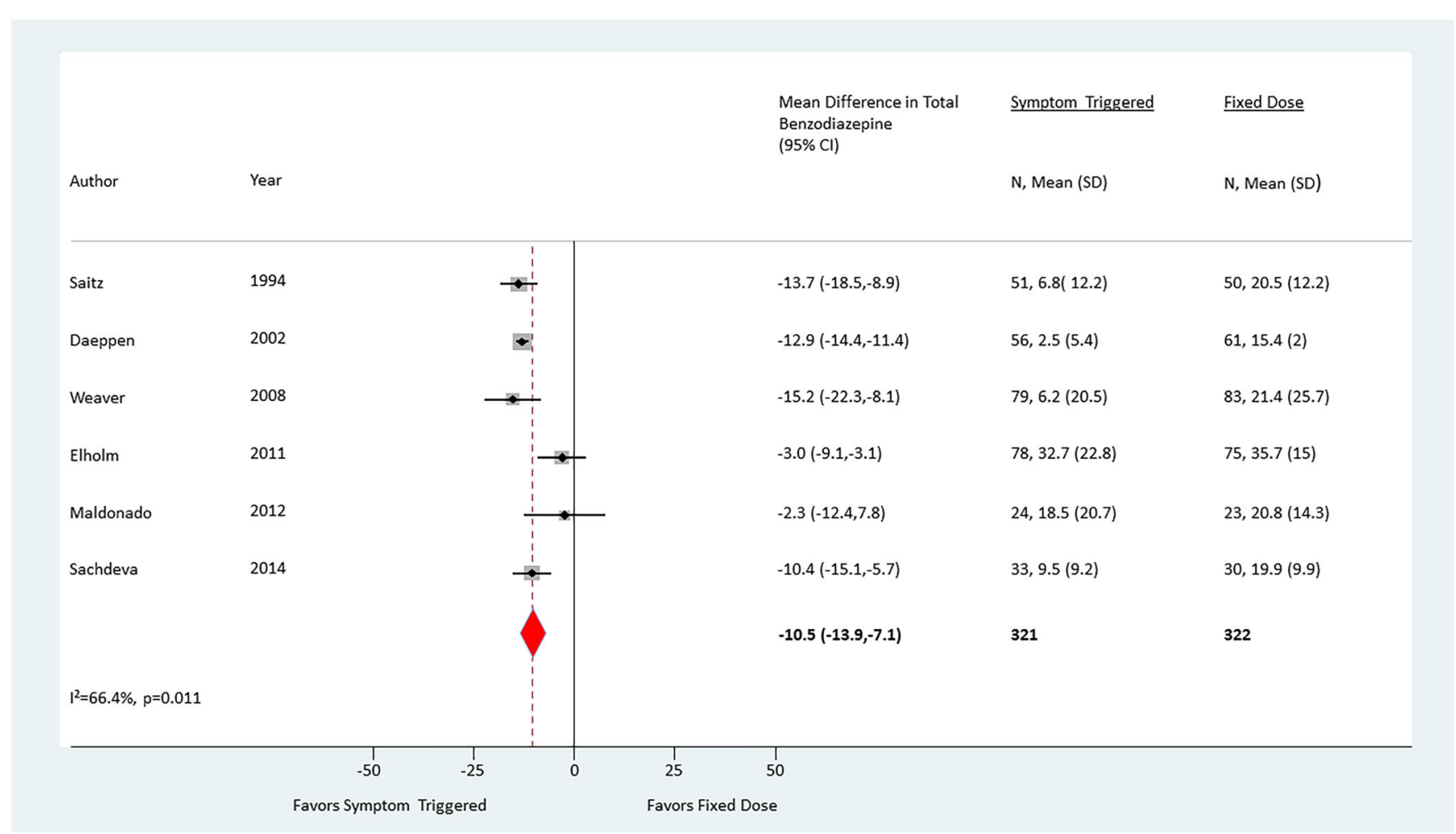

Figure 3 Difference in mean total benzodiazepine dose (mg lorazepam): symptom-triggered therapy (STT) vs fixed dose therapy (FDT).

Limitations of our review include the paucity of randomized controlled studies, small sample sizes, and low-risk study populations mentioned above. Applicability is further limited by the study exclusion criteria. For example, out of 280 admissions in one study, only 111 were eligible given exclusions for history of seizure (60), opiate withdrawal (28), using or withdrawing from benzodiazepines (19), beta blocker use (13), barbiturate use (1), or clonidine use (1).

Additional limitations were the clinical heterogeneity of the included studies the fact that we had to convert the different benzodiazepines used to lorazepam equivalents. Because of the limited number of studies, we did not explore heterogeneity using subgroup analysis or meta-regression. Similarly, we did not assess for publication bias.

\section{CONCLUSIONS}

In summary, there was insufficient evidence to determine the value of symptom-triggered therapy for the major outcomes of mortality, delirium, and seizure. There was moderate strength evidence that symptom-triggered therapy improved duration of therapy and total benzodiazepine dose in specialized detoxification centers of low-risk patients but the applicability of these studies was low for inpatient hospital settings. Given the high prevalence of alcohol use disorder and alcohol withdrawal syndrome in hospital settings, there is an urgent need for further studies to assess the optimal method of management of these conditions in the hospital.
Acknowledgements: The authors would like to thank reference librarians Jessica Patterson and Jennifer Martin at VACT and Minna Holleck for her Spanish translation.

Corresponding Author: Jürgen L. Holleck, M.D.; Department of Medicine, West Haven VA Hospital, Veterans Affairs Connecticut Healthcare System, 950 Campbell Ave, West Haven, CT 06516, USA (e-mail: Jurgen.Holleck@va.gov).

\section{Compliance with Ethical Standards:}

Conflict of Interest: The authors declare that they do not have a conflict of interest.

\section{REFERENCES}

1. Grant BF, Goldstein RB, Saha TD, et al. Epidemiology of DSM-5 Alcohol Use Disorder: Results From the National Epidemiologic Survey on Alcohol and Related Conditions III. JAMA Psychiatry. 2015;72(8):757-766.

2. Moore RD, Bone LR, Geller G, Mamon JA, Stokes EJ, Levine DM. Prevalence, detection, and treatment of alcoholism in hospitalized patients. JAMA. 1989;261(3):403-407.

3. Schuckit MA. Recognition and management of withdrawal delirium (delirium tremens). N Engl J Med. 2014;371(22):2109-2113.

4. Mayo-Smith MF, Beecher LH, Fischer TL, et al. Management of alcohol withdrawal delirium. An evidence-based practice guideline. Arch Intern Med. 2004;164(13): 1405-1412.

5. O'Connor PG, Schottenfeld RS. Patients with alcohol problems. $N$ Engl J Med. 1998;338(9):592-602.

6. Mayo-Smith MF. Pharmacological management of alcohol withdrawal. A meta-analysis and evidence-based practice guideline. American Society of Addiction Medicine Working Group on Pharmacological Management of Alcohol Withdrawal. JAMA. 1997;278(2):144-151.

7. Kosten TR, O'Connor PG. Management of drug and alcohol withdrawal. N Engl J Med. 2003;348(18):1786-1795.

8. Sullivan JT, Sykora K, Schneiderman J, Naranjo CA, Sellers EM. Assessment of alcohol withdrawal: the revised clinical institute 
withdrawal assessment for alcohol scale (CIWA-Ar). $\mathrm{Br} J$ Addict. 1989;84(11):1353-1357

9. Maldonado JR, Nguyen LH, Schader EM, Brooks JO 3rd. Benzodiazepine loading versus symptom-triggered treatment of alcohol withdrawal: a prospective, randomized clinical trial. Gen Hosp Psychiatry. 2012;34(6):611-617.

10. Hecksel KA, Bostwick JM, Jaeger TM, Cha SS. Inappropriate use of symptom-triggered therapy for alcohol withdrawal in the general hospital. Mayo Clin Proc. 2008;83(3):274-279.

11. Pletcher MJ, Fernandez A, May TA, et al. Unintended consequences of a quality improvement program designed to improve treatment of alcohol withdrawal in hospitalized patients. Jt Comm $J$ Qual Patient Saf. 2005;31(3): 148-157.

12. Finn KM, Greenwald J. Hospitalists and alcohol withdrawal: yes, give benzodiazepines but is that the whole story? J Hosp Med. 2011;6(8):435437.

13. Liberati A, Altman DG, Tetzlaff J, et al. The PRISMA statement for reporting systematic reviews and meta-analyses of studies that evaluate health care interventions: explanation and elaboration. PLoS Med. 2009;6(7):e1000100.

14. Higgins JP, Altman DG, Gotzsche PC, et al. The Cochrane Collaboration's tool for assessing risk of bias in randomised trials. BMJ. 2011;343:d5928.

15. Berkman ND, Lohr KN, Ansari M, et al. Grading the Strength of a Body of Evidence When Assessing Health Care Interventions for the Effective Health Care Program of the Agency for Healthcare Research and Quality: An Update. Methods Guide for Comparative Effectiveness Reviews (Prepared by the RTI-UNC Evidence-based Practice Center under Contract No. 290-2007-10056-I). AHRQ Publication No. 13(14)-EHC130-EF. Rockville, MD: Agency for Healthcare Research and Quality. November 2013. www.effectivehealthcare.ahrq.gov/reports/final.cfm.
16. Luo D, Wan $\mathbf{X}$, Liu J, Tong $\mathbf{T}$. Optimally estimating the sample mean from the sample size, median, mid-range, and/or mid-quartile range. Stat Methods Med Res. 2018;27(6):1785-1805.

17. Wan $\mathbf{X}$, Wang $\mathbf{W}$, Liu $\mathbf{J}$, Tong $\mathbf{T}$. Estimating the sample mean and standard deviation from the sample size, median, range and/or interquartile range. BMC Med Res Methodol. 2014;14:135.

18. Turner RC, Lichstein PR, Peden JG, Jr., Busher JT, Waivers LE. Alcohol withdrawal syndromes: a review of pathophysiology, clinical presentation, and treatment. J Gen Intern Med. 1989;4(5):432-444.

19. Saitz R, Mayo-Smith MF, Roberts MS, Redmond HA, Bernard DR, Calkins DR. Individualized treatment for alcohol withdrawal. A randomized double-blind controlled trial. JAMA. 1994;272(7):519-523.

20. Weaver MF, Hoffman HJ, Johnson RE, Mauck K. Alcohol withdrawal pharmacotherapy for inpatients with medical comorbidity. J Addict Dis. 2006;25(2):17-24.

21. Daeppen JB, Gache $\mathbf{P}$, Landry U, et al. Symptom-triggered vs fixedschedule doses of benzodiazepine for alcohol withdrawal: a randomized treatment trial. Arch Intern Med. 2002;162(10):1117-1121.

22. Elholm B, Larsen $\mathbf{K}$, Hornnes $\mathbf{N}$, Zierau F, Becker U. Alcohol withdrawal syndrome: symptom-triggered versus fixed-schedule treatment in an outpatient setting. Alcohol Alcohol. 2011;46(3):318-323.

23. Sachdeva A, Chandra M, Deshpande SN. A comparative study of fixed tapering dose regimen versus symptom-triggered regimen of lorazepam for alcohol detoxification. Alcohol Alcohol. 2014;49(3):287-291.

Publisher's Note: Springer Nature remains neutral with regard to jurisdictional claims in published maps and institutional affiliations. 